\title{
Evaluation of Mechanical and Tribological properties of Biowaste and Biowaste Based Silica Particulate Epoxy Composites
}

\section{Pranay}

KITS: Kakatiya Institute of Technology and Science

\section{S. Ojha}

KITS: Kakatiya Institute of Technology and Science

Raghavendra G ( $\nabla$ raghavendra.gujjala@gmail.com )

NIT Warangal https://orcid.org/0000-0003-0199-9576

G. Dheeraj

NIT Warangal: National Institute of Technology Warangal

\section{A. Anjali}

IIT Gandhinagar: Indian Institute of Technology Gandhinagar

\section{Research Article}

Keywords: Silica, Rice husk, Erosion, Mechanical properties, Microstructure.

Posted Date: May 17th, 2021

DOl: https://doi.org/10.21203/rs.3.rs-511554/v1

License: (9) This work is licensed under a Creative Commons Attribution 4.0 International License. Read Full License 


\section{Abstract}

This paper reports the mechanical-erosion wear properties of extracted silica from Biowaste (rice husk) and pure rice husk-filled epoxy composites. A comparison is made on the influence of dispersed silica and rice husk particles on the properties of the epoxy composites. The composites are fabricated by hand lay-up process. The specimens are tested as per the ASTM standards for three different filler loadings of each silica and rice husk separately $(2,4$ and $6 \mathrm{wt} \%)$. It is perceived that with the increase in the rice husk filler loading in epoxy, there is a decline in tensile, flexural, and erosion wear properties. It is also evident that, with the increase in silica content until $6 \%$, the tensile and flexural strength have displayed consistent enhancement. Alongside, erosion results confirm that the properties of the pure epoxy had exhibited transition from semi-brittle to ductile nature due to the addition of silica fillers.

\section{Introduction}

Composite materials inherently are observed to be possess good strength to weight ratio due to provision of altering manufacturing process and addition of new materials. The multifaceted properties of composite have extended their applications towards, aerospace, automotive and biomedical applications. However though, current scientific community is motivated towards development of these composite materials using filler particles derived from various metals as dispersion materials to improve the mechanical and tribological properties. There is an ample research cited in this context and excellent mechanical and tribological property enhancement is pursued. Recently, deriving fillers from biowaste received significant attention in the global community which can reduce the global warming. To surmount these challenges, it was identified that natural material and natural waste are the better alternate to replace the conventional materials because of their cost-effectiveness, eco-friendly, and bio compatible. In current work, Rice husk (RH) is one such agricultural waste which is abundantly available and that has almost $92 \%$ silica which can be used as reinforcement if it is extracted.

Natural material possess many advantages which lead the scientific community to conduct the research and develop new materials using these natural fibers, which also solves the problem of disposal of waste like RH [1]. Polymers had been using in industries and household activities but the use of natural fiber as a reinforcement increases few properties and decreases few other properties when compared to neat polymers so using natural fibers in the available form are not prove to be more economically beneficial. So, researchers are trying to modify the natural fibers and use as filler in composites.

Rice husk is the fibrous material which has some main components such as $\mathrm{CaO}, \mathrm{MgO}, \mathrm{Na}_{2} \mathrm{O}, \mathrm{Al}_{2} \mathrm{O}_{3}$ and $\mathrm{SiO}_{2}$. The bulk industrial applications of rice husk are due to its low bulk density, abrasiveness in nature, weather resistance and unique composition which has been discussed by various researchers [2]. Rice husk mainly contains amorphous $85-92 \%$ [3-4] of silica $\left(\mathrm{SiO}_{2}\right)$, resulting in direct combustion of rice husk. Silica is a non-crystalline phase in rice husk. However, the temperature of crystallization varies depending on the chemical composition of the rice husk. Rice husk is likely to be used as an insulating 
material in the production of organic chemicals, panel boards and activated carbon [5], and filler cementing materials [6].

Previous researchers have suggested the possibility of using rice husk as a filler for the manufacturing of biodegradable polymer composites $[7,8]$. Recently extensive research has been done on extracted silica particles for biological applications [9], energy storage, biological mediators and building materials [10, 11]. By increasing the use of engineering silica particles, it can be considered that engineering silica synthesis from renewable resources can improve stability. The use of silica from rice husk to synthesize engineered silica particles is not only economically beneficial, but also beneficial for reducing environmental problems.

Therefore, the use of these renewable agricultural wastes to make biodegradable polymers will solve environmental problems. The present study focuses primarily on the extraction of silica from rice husk and investigate the mechanical and wear properties of silica-based rice husk composites with pure rice husk composites. The different properties are examined and compared at different testing conditions, while varying the percentage of filler loading.

\section{Materials And Methods 2.1 Materials}

In the present investigation Rice husk (RH) which is used is collected from the local rice mill for reinforcement in composite. To remove the impurities the collected rice husk was cleaned with water and removed the moisture at $80^{\circ} \mathrm{C}$ in oven for 24 hours. Rice husk was used as the main source to produce Silica (SiO2) micro particles which is used as a secondary reinforcement material in the experiment.

Epoxy resin (LY556) has been used as the matrix material and HY-951 liquid was used as hardener for fabrication of composite. The casting was done in square mould having dimension $200 \times 180 \times 4 \mathrm{~mm}^{3}$.

\subsection{Purified Silica Extraction from Rice Husk (RH)}

The extraction of silica (silicon dioxide) can be done in a different way by controlling variables like total time of carburization and temperature at which it is carburized. Due to some major factors such as temperature, chemical treatment the structure of the obtained silica varies from amorphous to crystalline. Among various chemical treatment, hydrochloric acid is used as a convenient method to prepare high reactivity and purity silica having large surface area during precipitation [12]. Due to the pretreatment of fiber with hydrochloric acid, majority of the impurities are removed and silica produced completely white in color [13-14].

Raw $\mathrm{RH}$ was leached with $1 \mathrm{M} \mathrm{HCL}$ and calcined at $600^{\circ} \mathrm{C}$, the obtained silica is almost white in colour and had a purity index of 98.2 percent to 99.7 percent. The results showed that $\mathrm{HCl}$ leaching was more efficient than $\mathrm{H} 3 \mathrm{PO} 4$ or $\mathrm{H} 2 \mathrm{SO} 4$ in removing metal ions. Silica obtained from $\mathrm{RH}$ at temperatures ranging Loading [MathJax]/jax/output/CommonHTML/fonts/TeX/fontdata.js ge from 2.5 to 6 hours is the most common. 
In the current study, $\mathrm{HCl}$ treated rice husk $(\mathrm{RH})$ fiber were placed inside the ceramic crucible and placed inside the muffle furnace. The fiber was heated up to $600^{\circ} \mathrm{C}$ Carbonization temperature at a heating rate of $6^{\circ} \mathrm{C} / \mathrm{min}$ and held for one hour at the same temperature and it takes at least $6 \mathrm{~h}$ to reach close to room temperature. This process allowed us to obtain 95\% silica as shown in Fig. 1.

\subsection{Fabrication of composite}

The hand lay-up process is adopted to prepare the composites in the current work. The composites are prepared at the room temperature. The percentage of the filler are selected as $2 \mathrm{wt} \%, 4 \mathrm{wt} \%$ and $6 \mathrm{wt} \%$ of rice husk and silica. The composite plates are prepared to the dimensions of $180 \times 200 \times 4 \mathrm{~mm}^{3}$. The required amount of epoxy and the hardener are taken in glass as per the total volume calculation and the silica/rice husk particulates are mixed in the epoxy and hardener mixture with a mechanical stirring for 5 to $10 \mathrm{~min}$ for proper dispersion of filler in the epoxy polymer. The mixture then poured in a mold and an extensive care has taken to ensure that no leakage of epoxy through the mold takes place. After curing for 24 hours, the composites are cut as per the ASTM standards for various tests. The fabricated composites by using silica and Rice husk materials, details were quoted in the Table.1

Table. 1 Percentage details of filler and matrix items in composites fabrication

\begin{tabular}{|c|c|c|}
\hline Reinforcement/filler & Sample name & Composite composition \\
\hline \multirow[t]{3}{*}{ Rice husk } & $2 \%$ Rice husk & 2\%Filler + Epoxy \\
\hline & $4 \%$ Rice husk & 4\%Filler + Epoxy \\
\hline & $6 \%$ Rice husk & 6\%Filler + Epoxy \\
\hline \multirow[t]{3}{*}{ Silica } & $2 \%$ Silica & 2\%Filler + Epoxy \\
\hline & $4 \%$ Silica & 4\%Filler + Epoxy \\
\hline & 6\% Silica & 6\%Filler + Epoxy \\
\hline
\end{tabular}

The fracture analysis of specimen was performed from a scanning electron microscope (SEM), performed under higher vacuum and $15 \mathrm{kV}$ of accelerating voltage of secondary electron.

The Tensile testing of the produced samples was out carried out using a Universal testing machine (UTM) in compliance with ASTM D638. The dimensions of the Samples are $140 \times 10 \times 4 \mathrm{~mm}$ were tested a gauge length of $70 \mathrm{~mm}$ at a speed of $2 \mathrm{~mm} / \mathrm{min}$ and the flexural test was also conducted in the UTM in accordance with ASTM D790. The dimensions are $140 \times 20 \times 4 \mathrm{~mm}$ were tested at a speed of $2 \mathrm{~mm} / \mathrm{min}$. the compression test also conducted in UTM. The dimensions are $10 \times 10 \mathrm{~mm}$ were tested at a speed of $2 \mathrm{~mm} / \mathrm{min}$. The test method was repeated for five identical samples and the mean was taken.

\subsection{Erosion test:}


Erosion is a type of wear that causes material loss due to repetitive impact of micro solid particles. As per the ASTM G76 standards the erosion test rig was fabricated that was used in the present investigation. The specimens used for the application are cut to $25 \times 25 \times 4 \mathrm{~mm}$ dimensions. The test rig from the prepared composite layers consists of a particle feeder, an air compressor, and an air particle compartment and accelerator chamber. The compressed dry air is mixed with erosion sand particles and delivered in uniform proportions by applying a conveyor belt type feeder into the mixing chamber, which is then accelerated by sending it to the mixing nozzle, which is made up of tungsten carbide of diameter 5 $\mathrm{mm}$. These accelerated particles affect the sample, which can be placed at different angles to affect the particles with the help of an adjustable sample holder. To measure the velocity of the erosion particles, a rotating double disk is attached to the test instrument by this machine [15]. The samples used for the test were properly cleaned and dried in acetone and weighed to an accuracy of $0.001 \mathrm{~g}$ using an electronic balance after each test.

The erodent size used is $200 \pm 50$, erodent is silica sand, shape is angular, erosion feed rate is $2 \mathrm{~g} / \mathrm{min}$, impact velocity is $78 \mathrm{~m} / \mathrm{sec}$. impingement angles are $30,45,60$ and $90^{\circ}$.

\section{Results And Discussion}

The surface morphologies of the calcinated rice husk at $600^{\circ} \mathrm{C}$ were studied using FESEM setup by FEI Netherlands. The micrographs displayed in the Fig. 2 display that the sample consists of consists of the gathering of hexagonal block-like silicates with various size particles with shape stand almost same. As it is seen in higher magnifications it is clear that the shape is like a floret of cauliflower. The surface is very fluffy and it has loose accumulation of particles. It is reported in the literature that the dual size structures are vital in super hydrophobicity generation in material $[16,17]$.

Energy dispersive spectroscopy or EDX analysis of the calcinated rice husk confirms the maximum silica content.

\subsection{Mechanical Properties evaluation}

In composites the enhancement of the mechanical properties such as tensile, flexural, compressive etc. depend on several factors such as type of filler, matrix material, size or shape of the reinforcement, dispersion of filler in matrix, fiber orientation, filler concentration and adhesion between the matrix and filler etc.

\section{Tensile Properties}

Tensile properties play an important role to analyze the strength of any engineering material. The tensile tests were conducted of the fabricated samples according to ASTM standard at room temperature, using a universal testing machine (INSTRON).

The tensile test results of $\mathrm{RH}$ and Silica particle-based polymer composites with varying wt.\% (2 wt.\%, 4 
It is seen that with the addition of $\mathrm{RH}$ filler with polymer, the strength is substantially increasing at $2 \mathrm{wt} . \%$ compared to pure epoxy composite. But a sudden change was also observed that the higher filler loading ie $4 \mathrm{wt} . \%$ and $6 \mathrm{wt} . \%$ of $\mathrm{RH}$ had a negative impact on the tensile strength of the composite. Which occurs due to the weak interfacial bonding between the filler and the polymer, because the filler is hydrophilic whereas polymer is hydrophobic in nature. The compatibility of polymer and natural filler is not up to the mark.

On the other hand, $4 \mathrm{wt} . \%$ silica particle filler composites were found to be effective to improve the tensile properties of the composite. The filler-matrix interaction was found to be better in polymer composite when compared to pure matrix and rice husk filler composite. Because of calcination process at $600^{\circ} \mathrm{C}$, amorphous silica is formed, which is hydrophobic in nature. Epoxy is also hydrophobic in nature, so there is a good interfacial bonding occurs between the amorphous silica and pure polymer. Which leads to increase the strength of the composite. Further increasing of filler content, the strength of the composite decreased. It may be due to silica has a lower bulk density and larger average particle size which increases the filler content and start forming agglomerations.

Figure 4 illustrates the load-displacement curves of the tensile strength for neat epoxy, various filler loading $(2,4,6 w t \%)$ of rice husk and silica. The highest tensile failure load is observed $4 \mathrm{wt} \%$ silica filler composites followed by $2 \mathrm{wt} \%$ silica and $6 \mathrm{wt} \%$ silica. When the filler percentage increases from $2 \mathrm{wt} \%$ to $4 \mathrm{wt} \%$ of silica the resistance to failure also increases but at higher filer loading the load resistance is reduced. Where as in rice husk the maximum load is observed in $4 \mathrm{wt} \%$ followed by $2 \mathrm{wt} \%$ rice husk the least load is observed for $6 \mathrm{wt} \%$ rice husk filler loading. The results also indicate that the behavior of failure is not pure brittle where as for pure epoxy the failure is brittle which has less elongation.

Figure 5 illustrates the micrographs of the fracture surface samples of silica and rice husk for $4 \mathrm{wt} \%$ filler loading. It is clearly observed that the composite with rice husk filler has many cracks and filler pull out due to tensile loading is noticed this may be due to agglomerations and week interface between the filler and the matrix. But in silica filler no cracks are observed and the filler and matrix interface are good.

\section{Flexural properties}

Flexural test was carried out according to ASTM D790 standard method. Figure 6 shows flexural strength of the $\mathrm{RH}$ and silica particle-based polymer composite. It is observed from the figure that due to incorporation of $\mathrm{RH}$ fiber or silica particle with polymer the flexural strength increasing significantly as compared to polymer. Among all the filler concentration, $6 \mathrm{wt}$ \% silica particle-based polymer composite shows better strength. Normally silica has good resistance to deformation due to presence of hydrogen bond in composites. It is also observed that the flexural strength increases as the filer loading increases up to $6 \mathrm{wt} \%$ where as in rice husk as the filler loading increase from 4 to $6 \mathrm{wt} \%$ the strength decreases this is due to poor interfacial bonding between the fillers at higher filler loading.

In tensile strength $4 \mathrm{wt} \%$ filler loaded composites shows better strength where as in flexural $6 \mathrm{wt} \%$ shows Loading [MathJax]/jax/output/CommonHTML/fonts/TeX/fontdata.js in to low density polymers all the fillers are 
settled at lower level of the composites at the time of fabrication in higher filler loading some particles are settled in the lower layers some are distributed to the top layers and form like functional polymer composites which enhances the bending properties.

In natural fibers due to hydrophilic nature this type of distribution is not possible and a clear agglomeration of the fillers takes place which decreases the strength.

\section{Ultimate compressive strength}

The results of the compressive strength of $\mathrm{RH}$ and silica reinforced composites are presented in the Fig. 7. Compared to the neat polymer composite, the optimum compressive strength was found to be at 2 wt.\% for both filler composite. Furthermore, addition of filler at $4 \mathrm{wt} . \%$ and $6 \mathrm{wt} . \%$ reduces the compressive strength, which is due to the weak interlingual bond between the filler and the matrix material, resulting in a weak load transfer from the reinforcement, leading to failure.

Maximum ultimate strength was found at $62 \mathrm{MPa}$ in silica particle polymer composite followed by 57 $\mathrm{MPa}$ and $52 \mathrm{MPa}$ in $\mathrm{RH}$ and epoxy composite respectively. Further increased in silica particles with polymer, the strength is gradually decreasing. This may be due to the lower bulk density and larger average particle size of silica.

\subsection{Effect of Erosion wear on fabricated composite}

In the engineering field mostly, the behavior of the materials is grouped by two vital categories such as "Brittle and Ductile". Even though this grouping is not conclusive [18]. Among the several polymer matrix composite, thermoplastic polymer matrix composite generally shows ductility in nature because of peak erosion rate occurs at $30^{\circ}$ impact angle, since cutting mechanism is predominant in erosion. Even though thermosetting polymer matrix composites erode in a brittle manner with the peak erosion occurring at normal impingement angle ie. $90^{\circ}$. Still there is a controversy about this failure classification because erosive wear behavior sturdily depends on experimental conditions and the composition of the target material.

In the present work erosion tests is conducted for different compositions of RH filler such as $2 \mathrm{wt} . \%, 4$ wt. $\%$ and $6 \mathrm{wt} . \%$ composite at different impingement angle $\left(30^{\circ}, 45^{\circ}, 60^{\circ}\right.$ and $\left.90^{\circ}\right)$ and their respective erosion curves are plotted with keeping other parameters are constant (impact velocity $=72 \mathrm{~m} / \mathrm{s}$, stand-off distance $=10 \mathrm{~mm}$ and erodent size $=200 \pm 50 \mu \mathrm{m}$ ).

Figure 8 shows the dependence of erosion rate of RH filler epoxy composite with different filler composition at various impingement angle. Among different wt.\% of filler, $2 \mathrm{wt} . \% \mathrm{RH}$ filler epoxy composite shows minimum wear rate. It can be observed that the peak erosion rate occurs at $\theta=30^{\circ}$ impact angle for all the samples irrespective of filler content. This shows the ductile behavior of the RH polymer composite. As the literature articulates that the nature of the epoxy polymer is semi ductile $(\theta=$ $60^{\circ}$ ), but after incorporating of $\mathrm{RH}$ filler with epoxy, the behavior of the composite changes to ductile. It is Loading [MathJax]/jax/output/CommonHTML/fonts/TeX/fontdata.js er the erosion rate of the composites 
significantly increasing. It may be due to in $2 \mathrm{wt}$ \% filler the polymer content is more, so composite is taking some time to eroded but in higher content of filler the wear rate of the composite is more, it may be due to the rice husk is a soft fiber, so it is eroded easily.

The erosion wear rate of silica particle filler composites as a function of impingement angle $\left(^{\circ}\right)$ are shown in Fig. 9. It can be seen that reinforcing with silica particles reduces wear rate of the silica-epoxy composites quite significantly. As the filler content increases the wear rate of the Si-epoxy composite decreases. The $6 \mathrm{wt}$.\% silica particles filled composites, shows minimum wear while for both $2 \mathrm{wt} . \%$ and $4 \mathrm{wt} . \%$ silica content composites shows maximum erosion wear rate. The peak erosion occurs is found to be at $\theta=30^{\circ}$ which is purely ductility in nature. It is also important to note that the sample with minimum filler content exhibits better erosion resistance. Rather than of silica particle rice husk also consists of some hardest element such as $\mathrm{CaO}, \mathrm{MgO}$, which helps to increase the wear resistance of the composite.

The Fig. 10 shows the comparison of $\mathrm{RH}$ filler with Si particle based polymer composite. It is clearly observed that $6 \mathrm{wt}$ \% silica particle filler composite shows minimum wear rate as compared to other comosite.

\section{Conclusions}

In this study, the effect of the inclusion of silica and rice husk on the tensile, flexural, compression and erosion wear properties of neat epoxy composites were investigated for three different filler percentages. The key results indicated that. Incorporation of silica particles significantly increases the tensile, flexural and compression strength when compared to neat epoxy and rice husk filler composites. This indicated the perfect load transformation is occur in between the silica filler and polymer. At higher filler loading $6 \mathrm{wt} \%$ the tensile and flexural strength are decreases this is due to the agglomeration formed by the rice husk particles due to hydrophilic nature of the natural fiber. The maximum tensile strength is observed in $4 w t \%$ silica filler composites the maximum flexural strength is observed in $6 w t \%$ silica filler epoxy composites. Erosion results confirm that the properties of the pure epoxy changes from semi brittle to ductile nature due to addition of silica and rice husk fillers. In overall comparison of silica and Rice husk the silica filler composites show better properties in mechanical and tribological. Extraction of silica from the rice husk can has many applications when compared to pure rice husk.

\section{Declarations}

Ethics approval and Consent to participate: not applicable

Consent for publication: Yes

Availability of data and material: The experimental data are available and all the information is provided in the paper. 
Funding: No funding

Author contributions: Dr. Sahkuntala ojha, professor in the Mechanical Engineering Department, KITS, Warangal have framed the design and development of the project.

Dr. Raghavendra is one of the principle investigator of the project and also corresponding author for the current research paper, alongside proof reading and important insights were provided in revising the article with most appropriate suggestions.

Mr. Pranay V, Research scholar at Mechanical Engineering Department, KITS, Warangal have worked on processing of the fabrication and conducted all the studies and drafting the research article.

Dheeraj G, Research scholar in the Department of mechanical, National Institute of Technology, Warangal material characterization for microstructural studies which helped us in completing the part of a project on time.

Anjali A, Research scholar Department of mechanical engineering, IIT Gandhinagar, Palaj, India helped in the characterization and mechanical testing.

\section{Acknowledgments}

The authors would like to thank the chairman and Principal of KITS and Director of NIT-Warangal, faculty members and laboratory staff of Mechanical Engineering Departments for their support to completion of this work.

\section{Compliance with ethical standards:}

the research work is original work all the standards are taken in consideration

Conflict of interest: No conflict of interest

Research involving Human Participants and/or Animals: no animals or human studies are involved. Informed consent: not applicable

\section{References}

1. Hiloidhari M, Baruah DC (2011) Crop residue biomass for decentralized electrical power generation in rural areas (part 1): Investigation of spatial availability. Renewable and Sustainable Energy Reviews 15:1885-92.

2. Lasko K, Vadrevu K (2018) Improved rice residue burning emissions estimates: Accounting for practice-specific emission factors in air pollution assessments of Vietnam. Environmental pollution 236:795-806. 
3. Lee JH, Kwon JH, Lee JW, Lee HS, Chang JH, Sang BI (2017) Preparation of high purity silica originated from rice husks by chemically removing metallic impurities. Journal of Industrial and Engineering Chemistry 50:79-85.

4. Zulfiqar U, Subhani T, Husain SW (2015) Towards tunable size of silica particles from rice husk. Journal of Non-Crystalline Solids 429:61-9.

5. Mishra P, Chakraverty A, Banerjee HD (1986) Studies on physical and thermal properties of rice husk related to its industrial application. Journal of Materials Science 21:2129-32.

6. Aprianti E, Shafigh P, Bahri S, Farahani JN (2015) Supplementary cementitious materials origin from agricultural wastes-A review. Construction and Building Materials 74:176-87.

7. Battegazzore D, Bocchini S, Alongi J, Frache A (2014) Rice husk as bio-source of silica: preparation and characterization of PLA-silica bio-composites. RSC Advances 4:54703-12.

8. Yap SY, Sreekantan S, Hassan M, Sudesh K, Ong MT (2021) Characterization and Biodegradability of Rice Husk-Filled Polymer Composites. Polymers 13:104.

9. Halip JA, Lee SH, Tahir PM, Te Chuan L, Selimin MA, Saffian HA (2021) A Review: Chemical Treatments of Rice Husk for Polymer Composites 11:12425 - 1243.

10. Liu B, Li C, Cheng Z, Hou Z, Huang S, Lin J (2016) Functional nanomaterials for near-infraredtriggered cancer therapy. Biomaterials science 4:890-909.

11. Shen Y (2017) Rice husk silica-derived nanomaterials for battery applications: a literature review. Journal of agricultural and food chemistry 65:995-1004.

12. Chandrasekhar S, Pramada PN, Majeed J (2006) Effect of calcination temperature and heating rate on the optical properties and reactivity of rice husk ash. Journal of materials science 41:7926-33.

13. Chandrasekhar S, Pramada PN, Praveen L (2005) Effect of organic acid treatment on the properties of rice husk silica. Journal of Materials Science 40:6535-44.

14. Madrid R, Margarido F, Nogueira CA (2013) Valorisation of rice husk by chemical and thermal treatments. InMaterials Science Forum 730:659-66. Trans Tech Publications Ltd.

15. Om Prakash M, Raghavendra G, Panchal M, Ojha S, Anji Reddy B (2018) Effects of environmental exposure on tribological properties of Arhar particulate/epoxy composites. Polymer Composites 39:3102-9.

16. Bok HM, Shin TY, Park S (2008) Designer binary nanostructures toward water slipping superhydrophobic surfaces. Chemistry of Materials 20:2247-51.

17. Wang M, Chen C, Ma J, Xu J (2011) Preparation of superhydrophobic cauliflower-like silica nanospheres with tunable water adhesion. Journal of Materials Chemistry 21:6962-7.

18. Boggarapu V, Gujjala R, Ojha S (2020) A critical review on erosion wear characteristics of polymer matrix composites. Materials Research Express 7:022002.

\section{Figures}




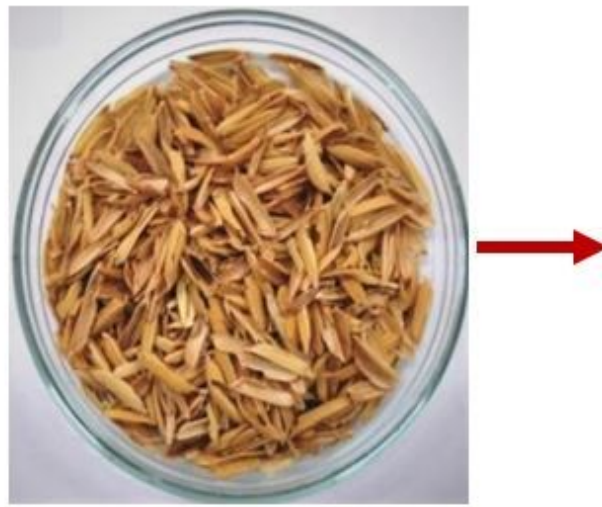

Raw Rice Husk (RH)

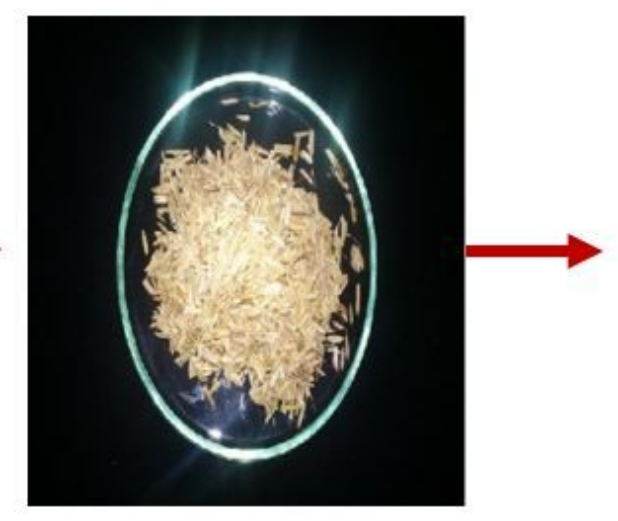

HCl treated Rice Husk
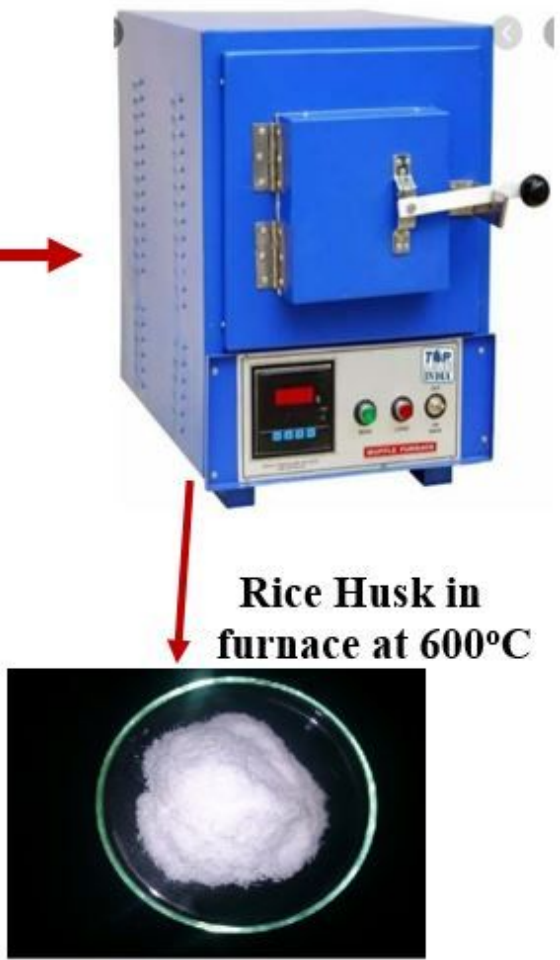

Micro Silica

Figure 1

Silica extraction process from rice husk.

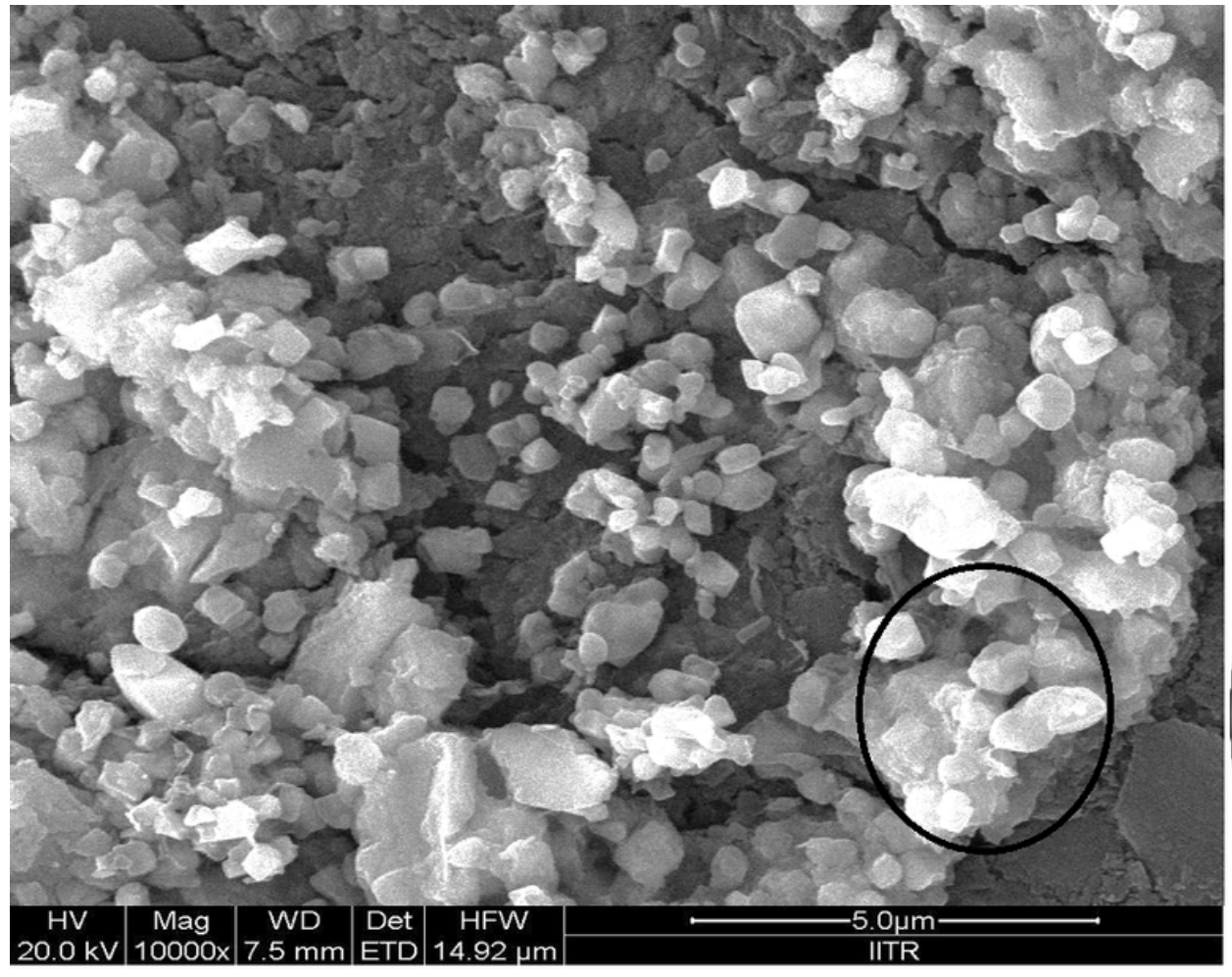

(a)

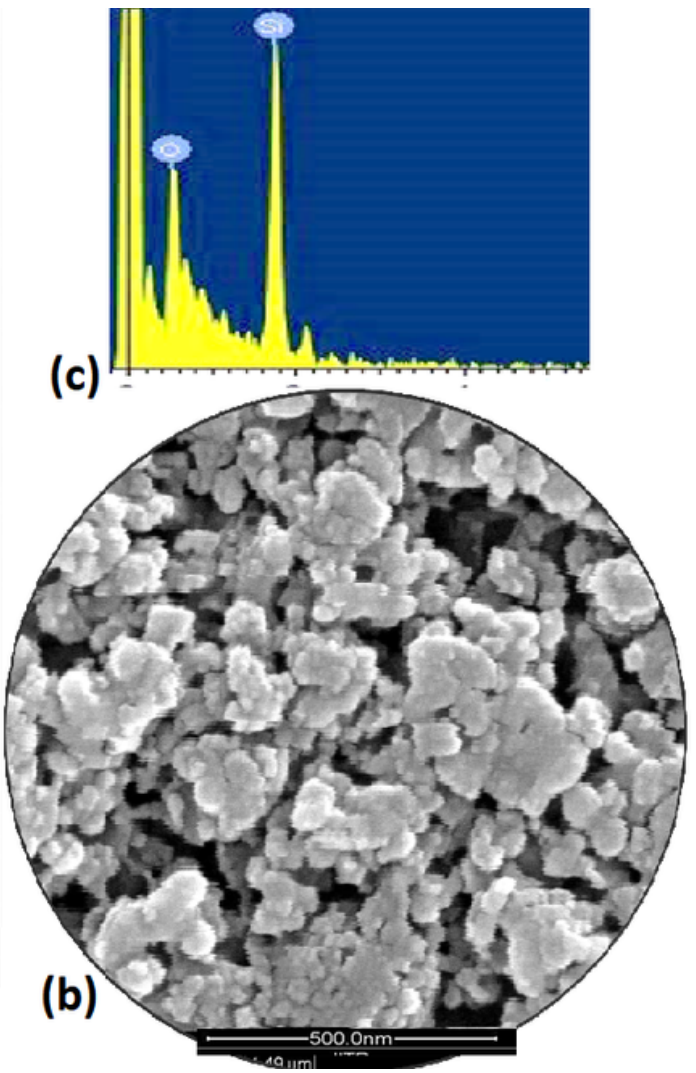


Figure 2

Field Emission Electron Scanning Microscope (FESEM) images of the sample calcined at $600^{\circ} \mathrm{C}$ (a) 10000X magnification (b) 100000Xmanification and (c) EDX spectra of the sample.

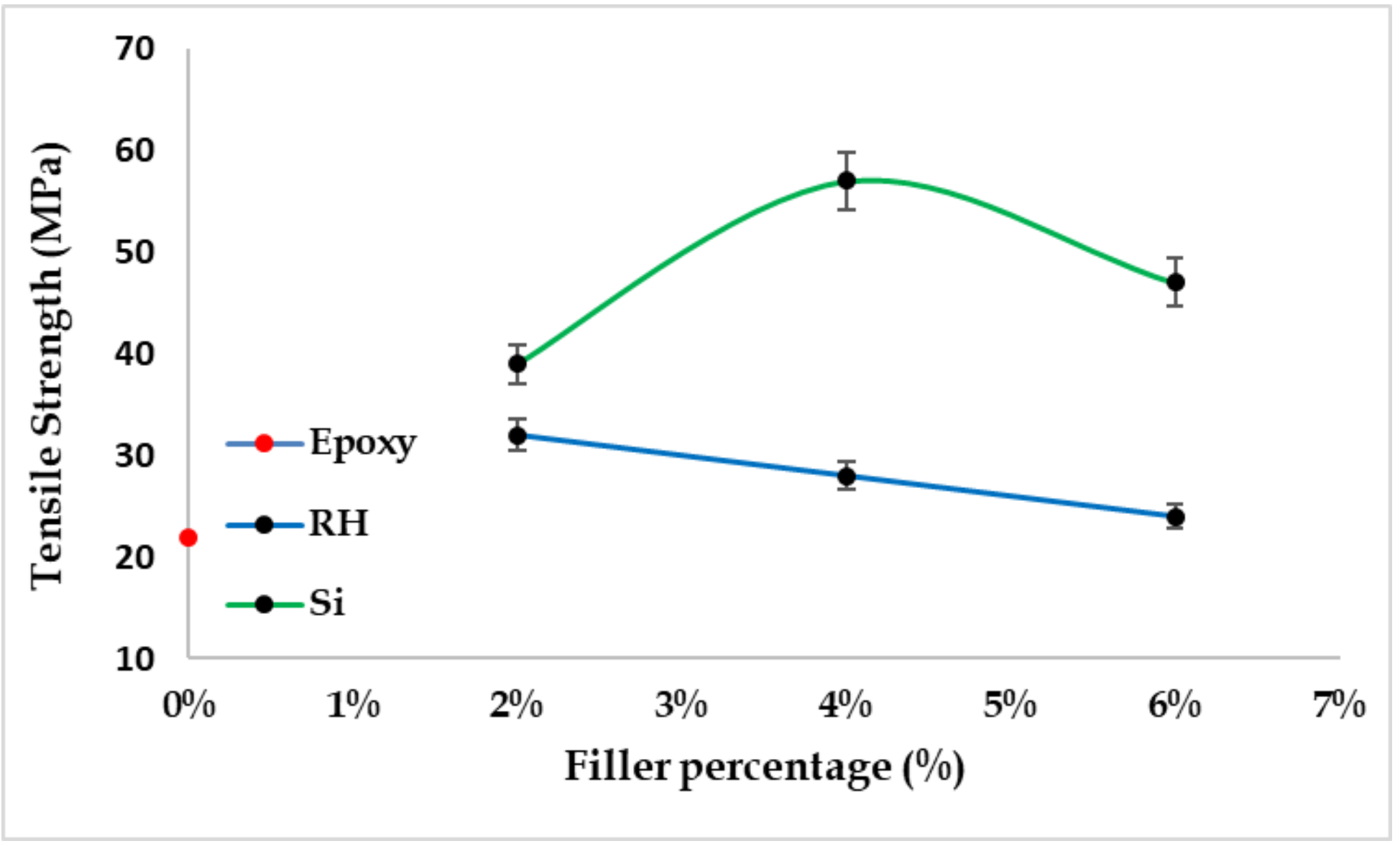

Figure 3

Tensile strength of composites 


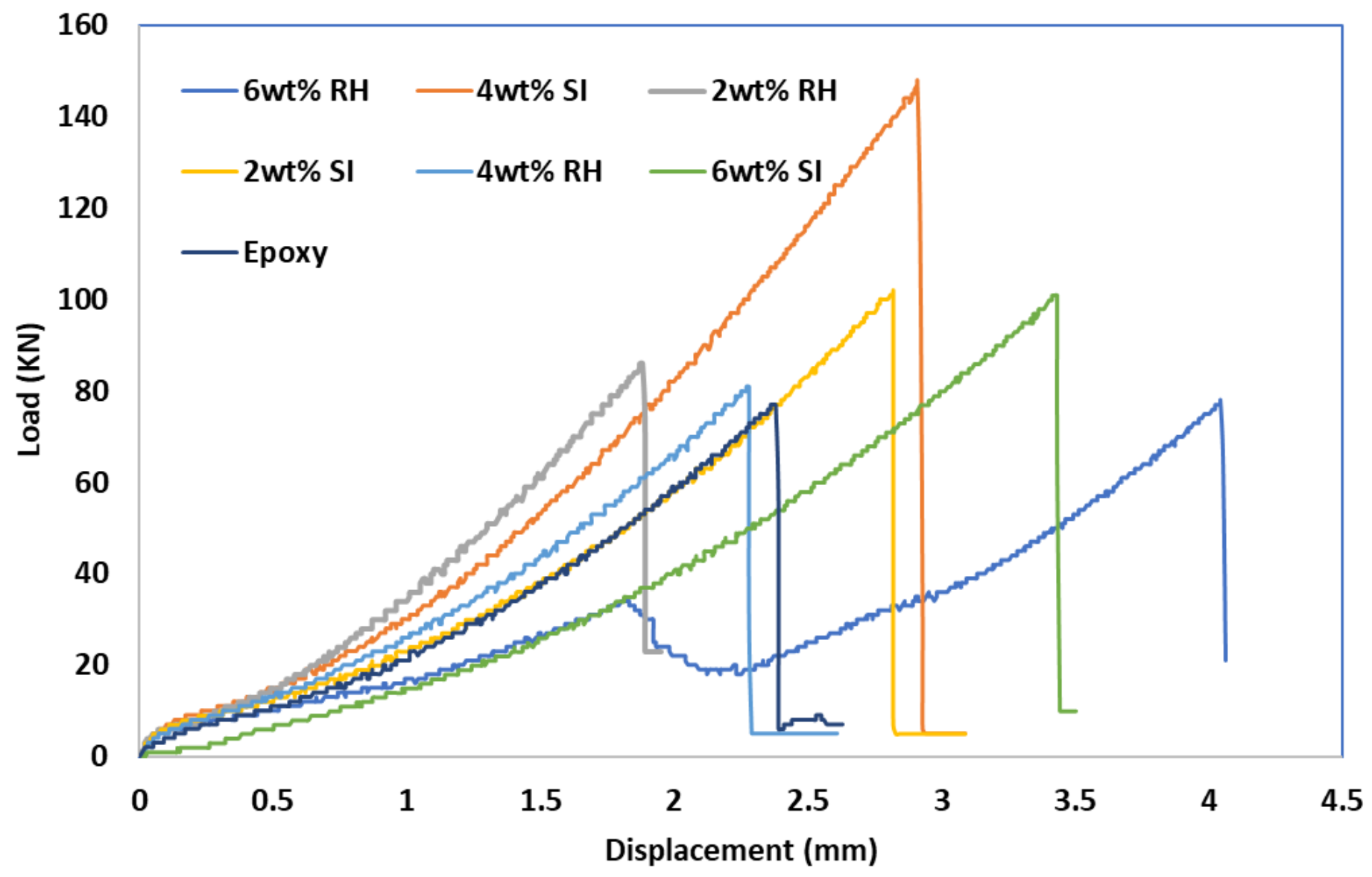

Figure 4

Load vs displacement (Tensile) for different composites
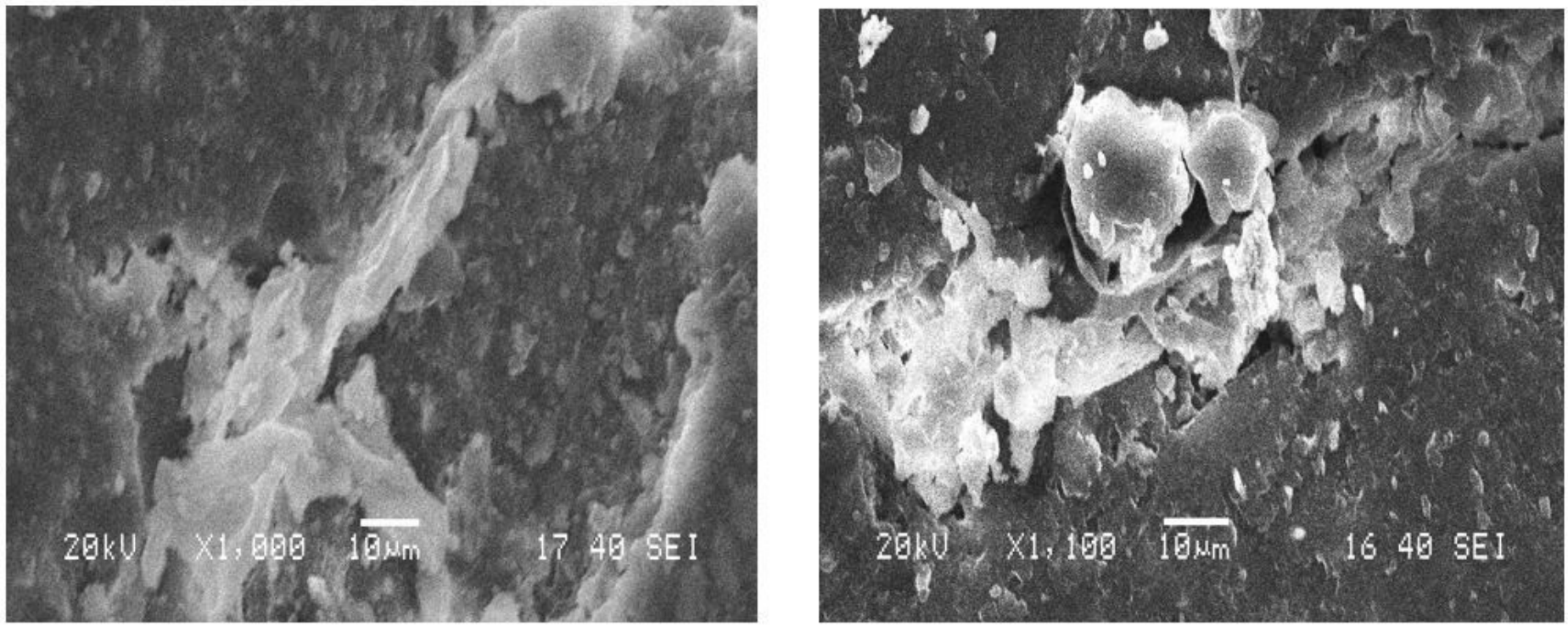

Figure 5 


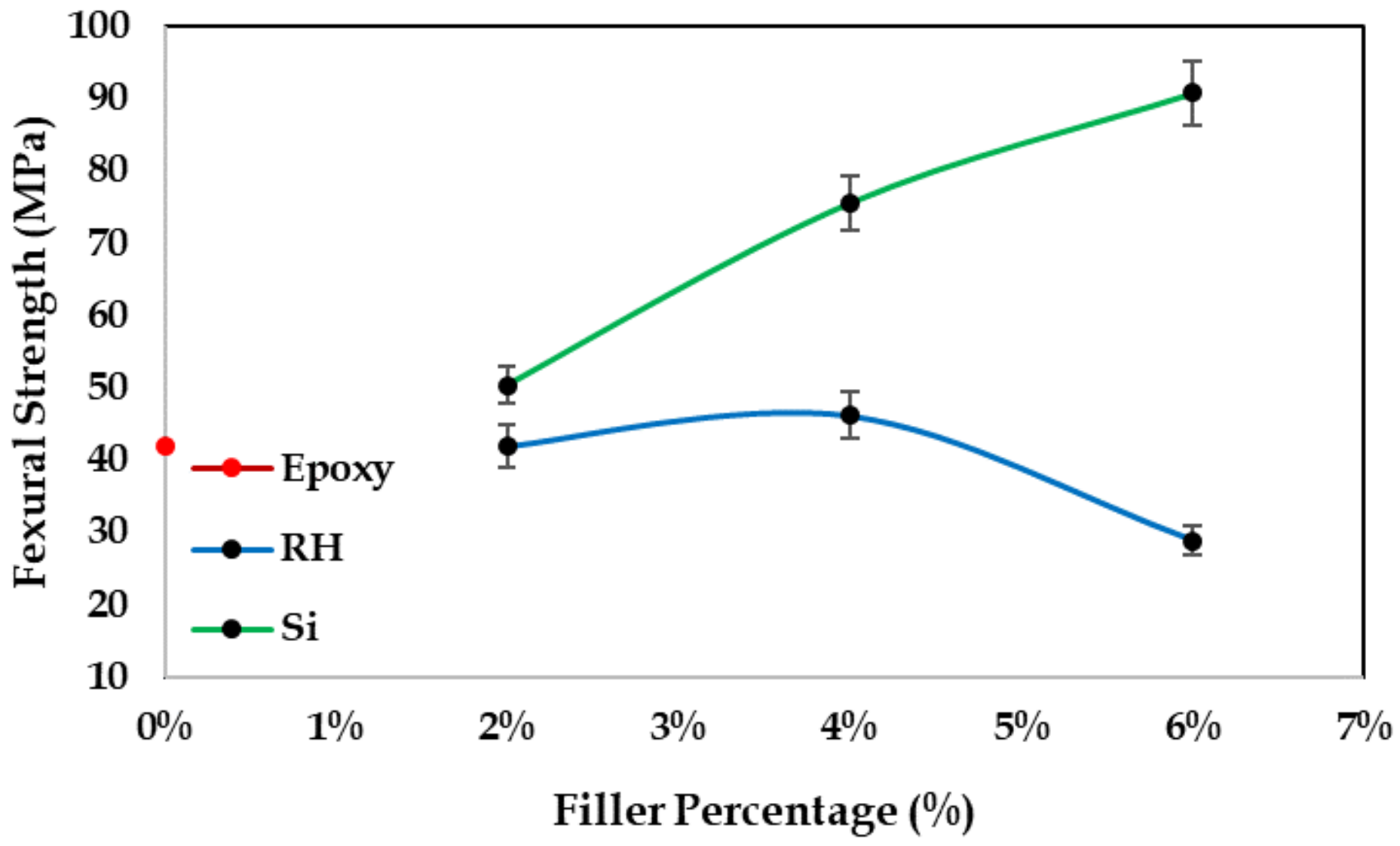

Figure 6

Flexural strength of composites 


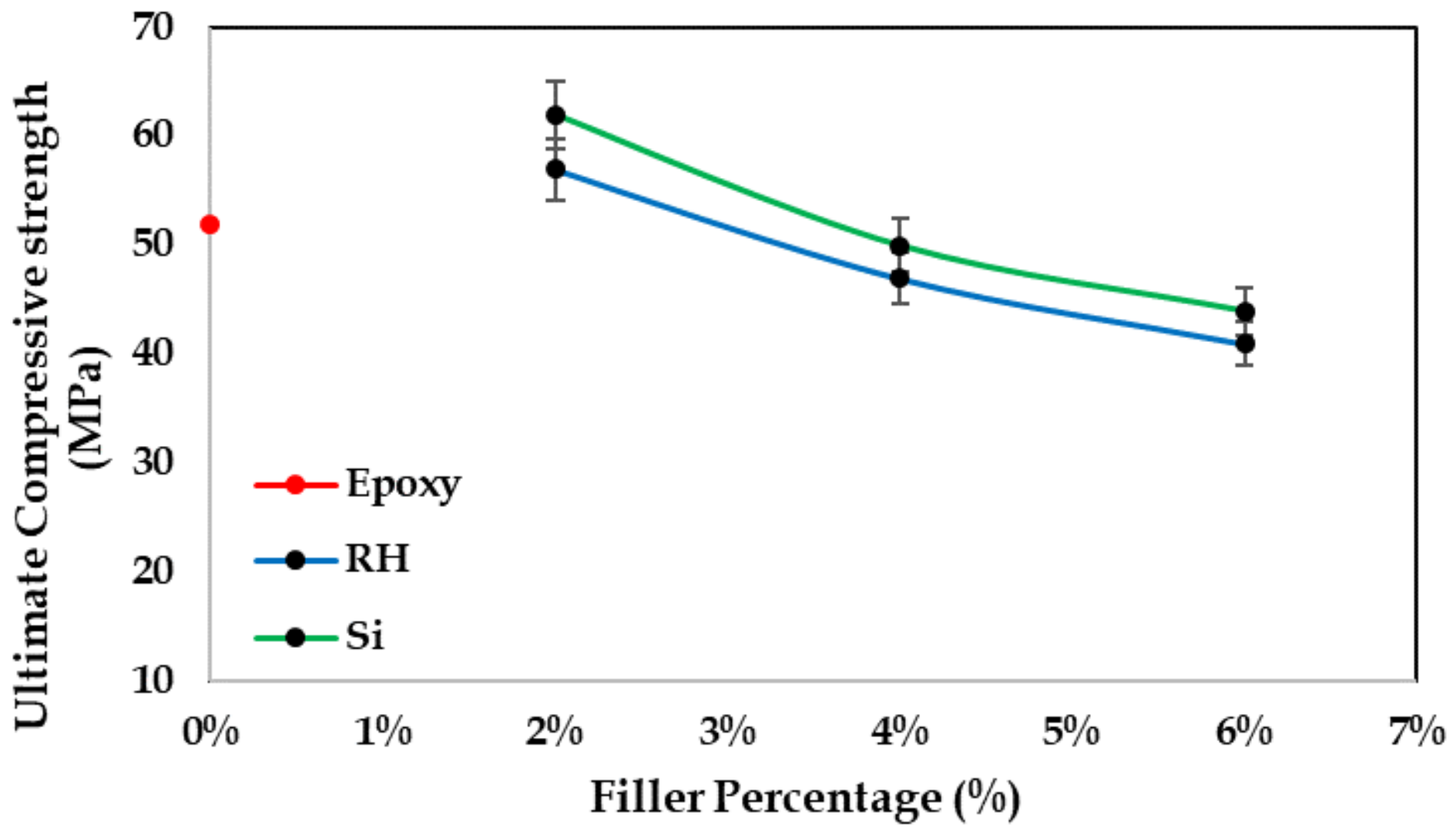

Figure 7

compression strength of composites 


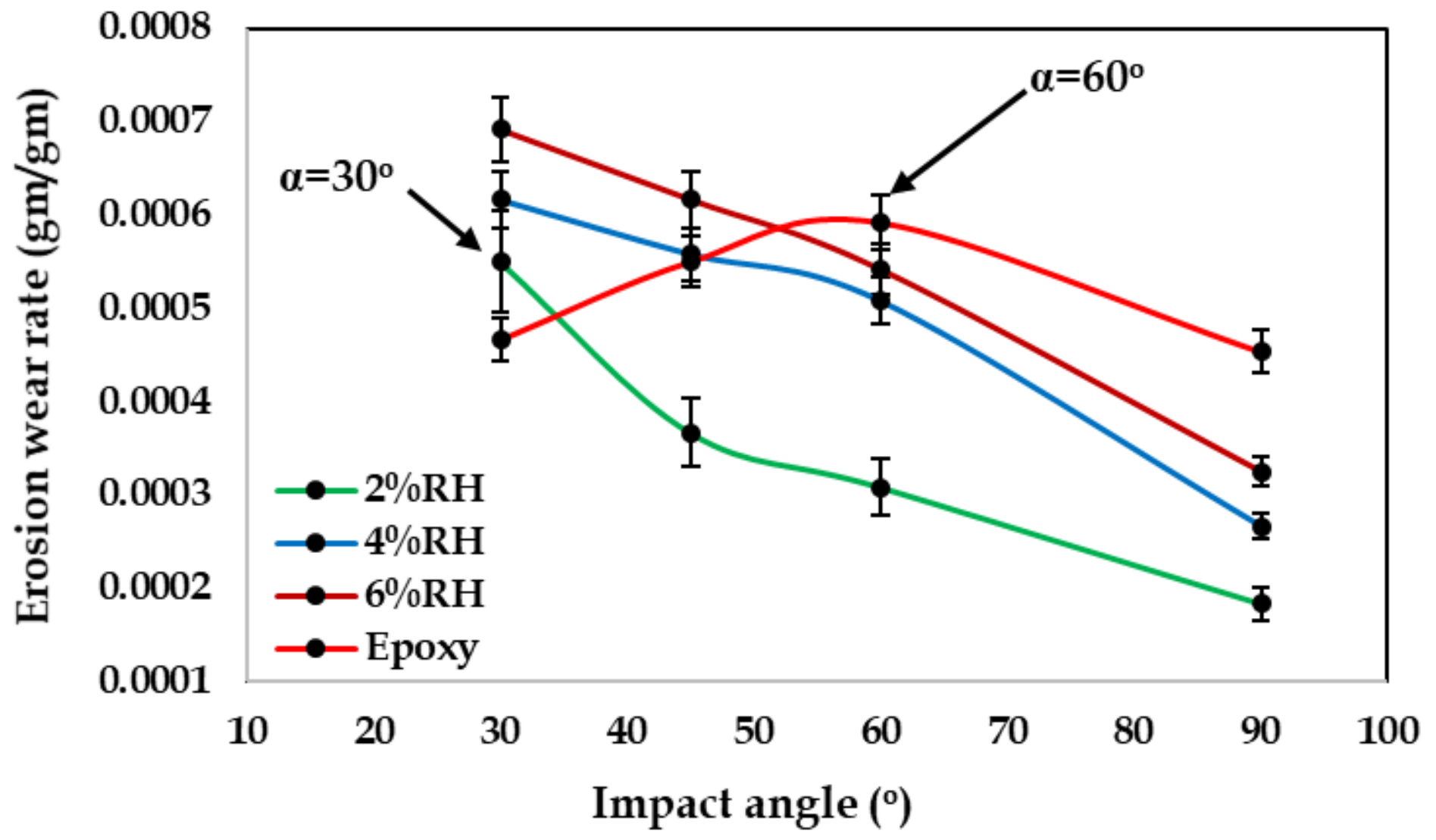

Figure 8

erosion wear of Rice husk particulate composites 


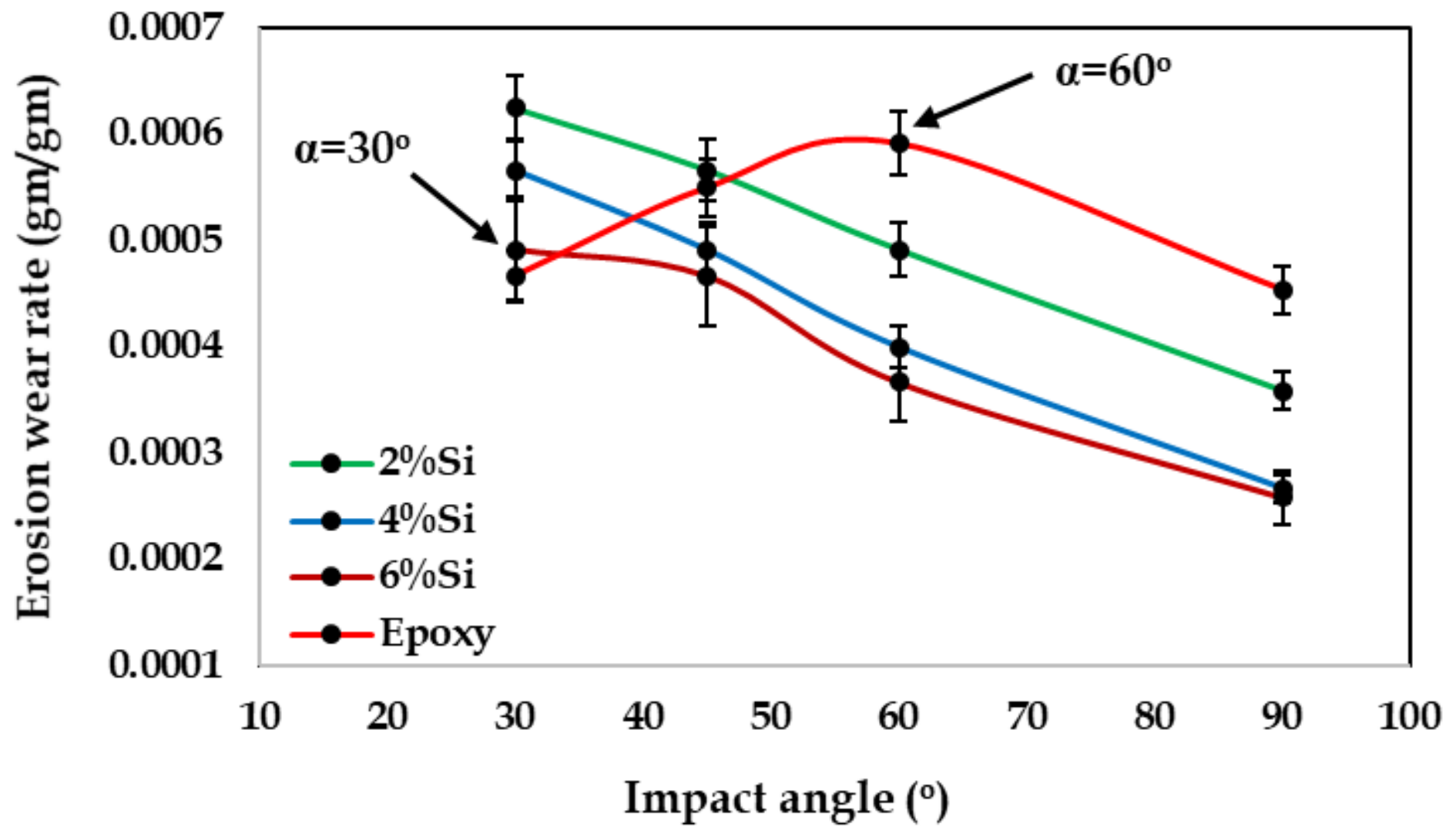

Figure 9

erosion wear of Silica particulate composites 


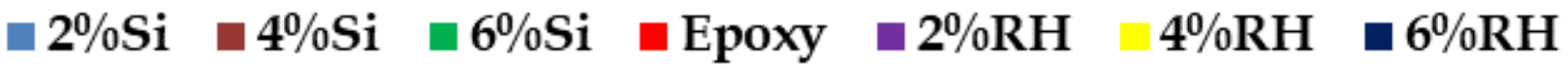

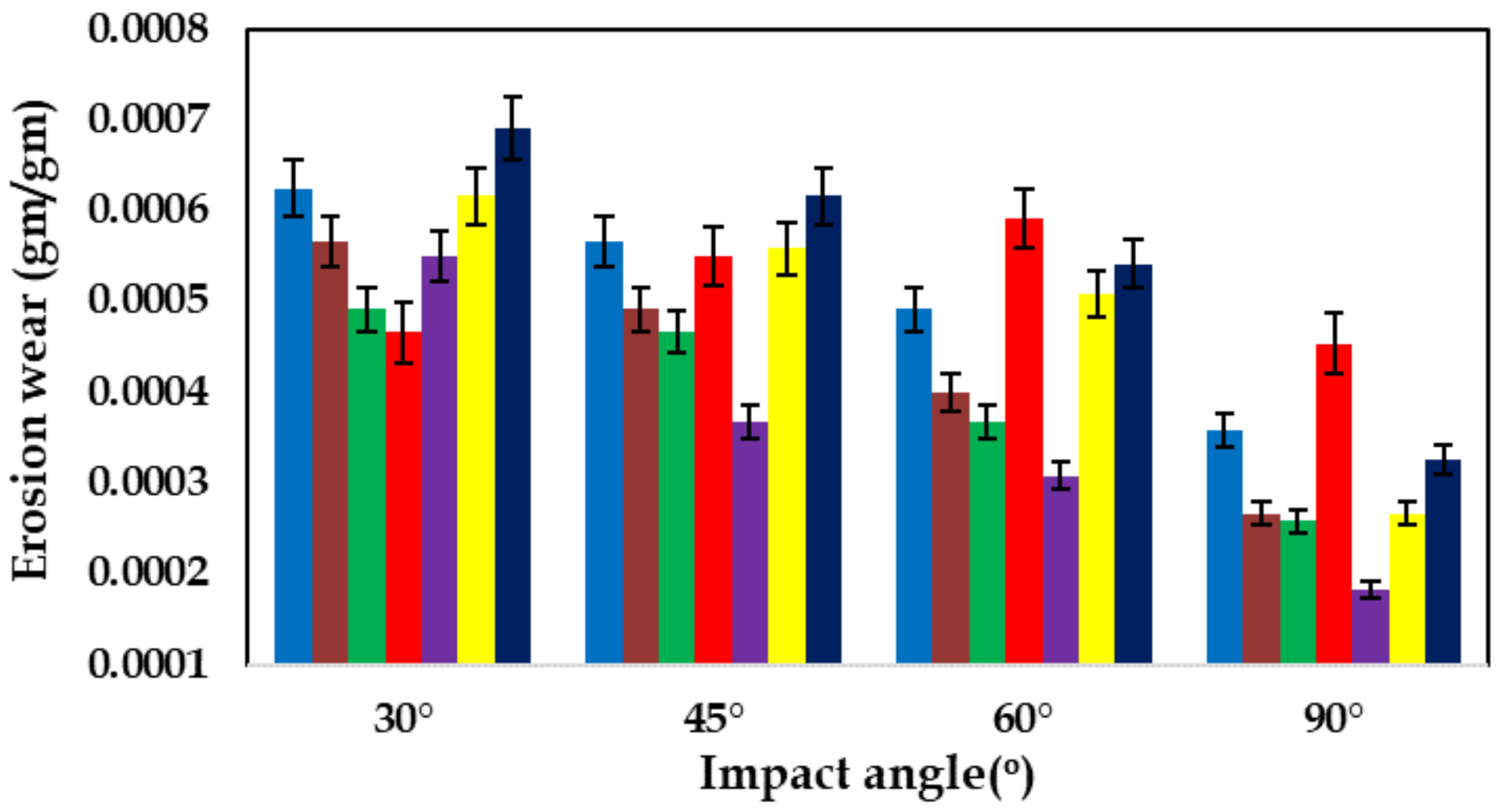

Figure 10

Comparison of erosion wear of silica and Rice husk particulate composites 